\title{
Immediate Effect of Anterior-to-posterior Talocrural Joint Mobilization with Elastic Taping on Balance Ability in Stroke Patients
}

\author{
Shin-Jun Park, PT, Ph.D • Soon-Hee Kim, PT, Ph.D. ${ }^{1 \dagger}$ \\ Department of Physical Therapy, Gang Dong University \\ ${ }^{1}$ Department of Physical Therapy, Yong-in University
}

Received: May 6, 2018 / Revised: May 9, 2018 / Accepted: June 4, 2018

(C) 2018 J Korean Soc Phys Med

\section{| Abstract |}

PURPOSE: Stroke patients have reduced balance ability due to a lack of motion in the ankle joint. Elastic taping assists movement, and joint mobilization, a form of passive movement, enhances mobility. The purpose of this study was to determine the immediate effects on balance ability after anterior-to-posterior (A-P) talocrural joint mobilization combined with elastic taping in stroke patients.

METHODS: Twenty stroke patients were divided into two groups: a joint mobilization with taping group (experimental group, $\mathrm{n}=10$ ) and an elastic taping only group (control group, $\mathrm{n}=10$ ). The experimental group underwent anteroposterior mobilization of the talus and elastic tape was applied to the calf and tibialis anterior muscles. The control group had elastic tape applied. Dynamic balanced abilities were assessed by using the BioRescue system. After 30 minutes of intervention, the forward, backward, left side, and right side sway areas

†Corresponding Author : Soon-Hee Kim shkim2776@nate.com, http://orcid.org/0000-0003-3999-3452 This is an Open Access article distributed under the terms of the Creative Commons Attribution Non-Commercial License (http://creativecommons.org/licenses/by-nc/3.0) which permits unrestricted non-commercial use, distribution, and reproduction in any medium, provided the original work is properly cited. $\left(\mathrm{mm}^{2}\right)$ were measured.

RESULTS: Only the experimental group showed a significant increase in forward sway area after intervention. However, no significant differences were detected between the two groups.

CONCLUSION: This study shows that A-P talocrural joint mobilization combined with elastic taping has a positive effect, producing an immediate increase in the forward balance ability of stroke patients. However, this study did not examine joint mobilization alone. In subsequent studies, it is necessary to examine the effect of joint mobilization only on balance in stroke patients.

Key Words: A-P talocrural joint mobilization, Balance, Elastic taping, Stroke

\section{Introduction}

Stroke patients can have various ankle-related symptoms including weakness of the tibialis anterior, spasticity of the gastrocnemius (Lin et al., 2006), and asymmetry and thickening of the anterior talofibular ligament (Yildizgoren et al., 2017). Such ankle impairment leads to a lack of ability to modify ankle strategies, decreases ankle proprioception, and results in tibialis anterior and calf 
muscle imbalance (Oliveira et al., 2008).

Ankle joint mobilization has recently been used as an intervention for stroke patients with poor balance, and elastic taping has been used as an effective treatment method for supporting the ankle joint (An and Jo, 2017; Kim and Lee, 2018; Koseoglu et al., 2017; Park, 2017).

Joint mobilization, an orthopedic manual physical therapy method for producing passive movement, has a neurophysiological pain-reducing effect and a mechanical effect that directly increases joint movement. Maitland's joint mobilization uses a basic concept, referred to as the brick wall theory, that provides an evidence-based approach to the relationship between the theoretical background and clinical symptoms (Hengenveld and Banks, 2005). Anterior-to-posterior (A-P) talocrural joint mobilization changes talus translation and increases the dorsiflexion range of motion (ROM) (Landrum et al., 2008). A-P ankle joint mobilization applied to the ankle of the stroke patient has been shown to be effective in restoring balance ability, as indicated by increased dorsiflexion ROM, plantar flexor strength, and stability limits (An and Jo, 2017).

Elastic tape applied to the stroke patients can support muscle function and joint structure, as well as provide proprioceptive feedback (Jaraczewska and Long, 2006). Elastic tape attached to the tibialis anterior can improve the lower extremity function, ambulation capacity, gait, and reduce spasticity of motor recovery (Koseoglu et al., 2017). Calf muscle taping can reduce sway amount and sway velocity in the anteroposterior plane (Cortesi et al., 2011). Furthermore, such taping has few side effects, can be used simultaneously with other interventions, and has a carryover effect when applied along with therapeutic exercises, which can prolong the therapeutic effect (Park, 2017).

The effects of joint mobilization and taping on pulmonary function and chest expansion (Park et al., 2017), as well as on wrist range of motion (ROM), spasticity, and strength of stroke patients (Park and Youn, 2017) have been demonstrated.

Despite the advantages of these therapeutic approaches, few studies have been conducted to determine balance ability changes resulting from simultaneous joint mobilization and elastic taping. Decreased balance and gait are the most serious problems encountered by stroke patients and are essential prerequisites for walking (Middleton et al., 2017). This study investigated a combined orthopedic manual physical therapy method for rehabilitation of stroke patients, and the results indicated that there was a difference in balance ability of stroke patients between applying A-P talocrural joint mobilization with elastic taping and elastic taping alone.

\section{Methods}

\section{Participants}

The present study included 20 patients diagnosed with stroke and admitted to a rehabilitation hospital in Gyeonggi-do, Korea. The selection criteria were: stroke $>6$ months and $<24$ months, a score $\geq 24$ in the Korean version of the Mini-Mental State Examination (Kang et al., 1997), a passive dorsiflexion ROM $\geq 0^{\circ}$ (Norkin and White, 2009), an Ashworth scale grade of $\leq 2$ (Bohannon and Smith, 1987), ability to stand alone for $\geq 30 \mathrm{~s}$, and hypomobility indicated by a talus A-P glide test (Denegar et al., 2002). Patients with a history of skin disease or orthopedic surgery on an ankle joint were excluded from the study. The 20 subjects were divided into two groups $(\mathrm{n}=10)$ : the experiment group underwent joint mobilization and elastic taping and the control group $(\mathrm{n}=10)$ underwent taping alone. The general characteristics of the study subjects are summarized in Table 1. All subjects voluntarily signed the study consent forms. The study was approved by the Committee on Bioethics of Yong-in University (2-1040966-AB-N-01-20-1803-HSR-098-2).

\section{Measurements methods and device}


Table 1. Subject Characteristics

\begin{tabular}{cccc}
\hline Classification & Experimental group $(\mathrm{n}=10)$ & Control group $(\mathrm{n}=10)$ & $\mathrm{P}$ \\
\hline Gender (male/female) & $8 / 2$ & $6 / 4$ & .329 \\
Paretic side (left/right) & $8 / 2$ & $5 / 5$ & .160 \\
Disease duration (month) & $11.30 \pm 2.45^{\text {a) }}$ & $10.80 \pm 2.86$ & .680 \\
Age (years) & $60.10 \pm 9.12$ & $63.30 \pm 7.95$ & .414 \\
Weight (kg) & $69.6 \pm 9.51$ & $68.4 \pm 10.93$ & .796 \\
K-MMSE $^{\text {b) }}$ (point) & $27.00 \pm .81$ & $26.60 \pm 1.07$ & .361 \\
MAS $^{\mathrm{c}}$ (point) & $.86 \pm .77$ & $.83 \pm .75$ & .773 \\
Dorsiflexion ROM $^{\mathrm{d})}$ (degree) & $6.36 \pm 3.34$ & $5.33 \pm 3.72$ & .274 \\
\hline
\end{tabular}

${ }^{\text {a) }}$ Values are means \pm SD

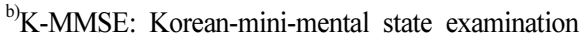

${ }^{c}$ MAS: Modified Ashworth scale

${ }^{\mathrm{d})}$ Dorsiflexion ROM: Dorsiflexion range of motion

\section{1) Balance ability}

In this study, dynamic balance ability was assessed by using a BioRescue system (AP1153, SyCoMORe, France). During assessment, subjects were instructed to pose with their feet on the force plate and move their center of gravity in the direction of randomly assigned arrows on the computer screen. Forward, backward, and left and right sides sway areas $\left(\mathrm{mm}^{2}\right)$ were determined. Subjects were allowed to have a computer monitor on the front. Subjects were instructed to follow the arrows on the screen and move the center of pressure to a point as far as possible from the start position. The subject maintains that balance position while the arrow is displayed and then returns to the start position when the arrow disappears. When an arrow in another direction appears, the same procedure is followed. The test-retest reliability of the limits of stability test results obtained from the BioRescue system is reported to be high (ICC=.78-.91, Chien et al., 2007; Liston and Brouwer, 1996; ICC=.84, Song and Park, 2016).

\section{Experimental design}

\section{1) A-P talocrural joint mobilization}

Five sets of A-P talocrural joint mobilization were

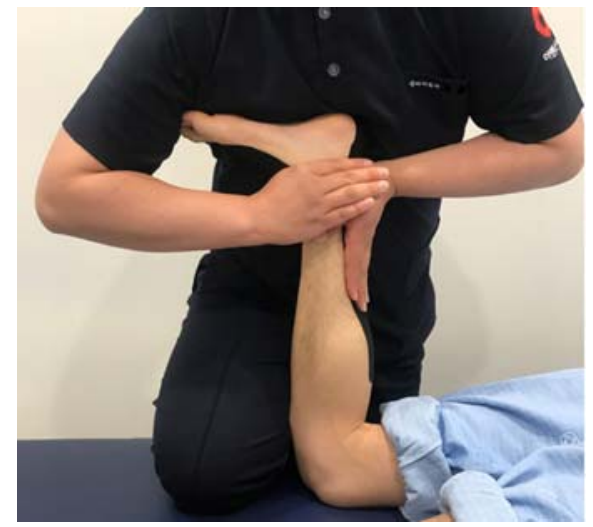

Fig. 1. A-P talocrural joint mobilization position

performed for $2 \mathrm{~min}$ followed by a $1 \mathrm{~min}$ rest period (15 min total) were applied to the experimental group. Prior to intervention, the subjects flexed the knee joint $90^{\circ}$ while lying on their stomach, and the researcher then applied A-P mobilization to the grade III paralyzed talus (Hengenveld and Banks, 2005) (Fig. 1).

\section{2) Elastic taping}

Taping was performed by applying elastic tapes (Kinesiology 3NS Tape, TS, Korea) to the paretic side of the calf muscle and tibialis anterior muscle of the patients in both groups. First, calf muscle taping was performed 


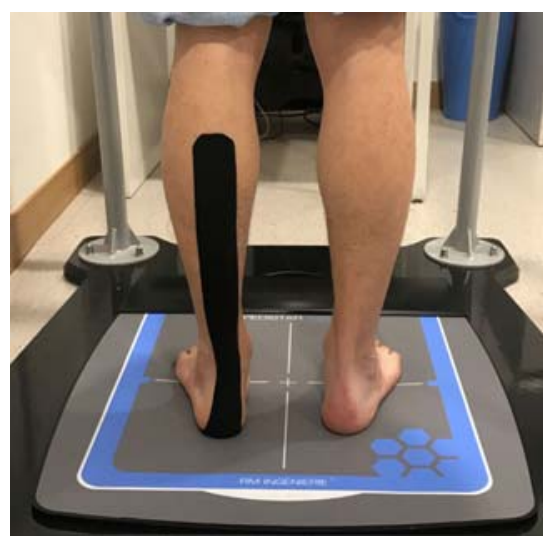

Fig. 2. Calf muscle tape placement

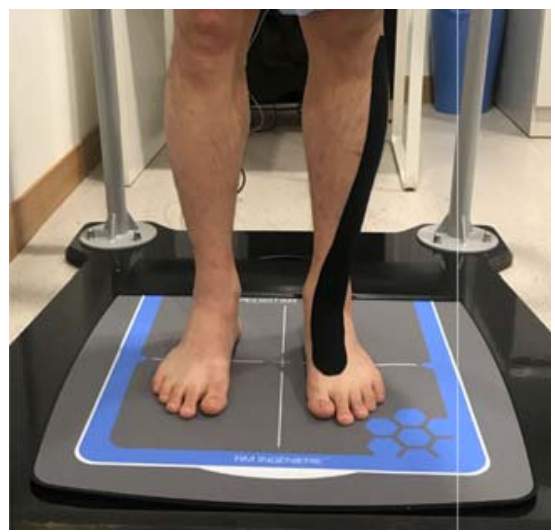

Fig. 3. Tibialis anterior muscle tape placement

on subjects in a prone position with the knee joint flexed and the ankle joint neutralized. One end of the tape was attached to the plantar surface of the heel, and the other end was the first of the calf (Fig. 2). During application, the tape was stretched by $50-75 \%$ prior to attachment to the Achilles tendon area. The ends and ends of the tape did not apply stretch (Cortesi et al., 2011). Second, tibialis anterior muscle taping was performed with the subject in the supine position. The tape was attached to paretic leg from the region of the origin to area of the insertion of tibialis anterior muscle (Koseoglu et al., 2017) (Fig. 3).

\section{Statistical Analysis}

In this study, the Kolmogorov-Smirnov test was used to determine normality. Descriptive statistics were used for assessment of the general characteristics of the subjects. The paired t-test was used to assess differences in the effects of intervention within each group, and the independent t-test was used to assess differences between groups. For statistical analyses, Statistical Package for the Social Sciences Version 21.0 (SPSS Inc, Chicago, IL, USA) was used with the significance level of alpha set at .05 .

\section{Results}

\section{Comparison of balance ability before and after intervention}

No significant differences were detected among all of the variables in the control group $(p>.05)$, but forward sway area was significantly increased in the experimental group $(p<.05)$. No significant differences were detected between the two groups $(p>.05)$ (Table 2).

\section{Discussion}

Stroke patients exhibit increased postural sway, which is associated with falls (Song et al., 2010). Balanced rehabilitation after stroke is important because the quality of life is reduced in stroke patients who have experienced falls (Song et al., 2010; Lee and Park, 2016). This study was conducted to evaluate the effect of ankle joint mobilization and lower leg elastic taping on balance ability in stroke patients with hypomobility of the ankle joint. The results of this study indicated there were no significant changes in any of the balance variables in the elastic tape only (control) group. In contrast, there was a significant increase in the forward sway area of the combined A-P joint mobilization and elastic taping (experimental) group. However, there was no significant difference in sway amounts between the two groups.

Elastic taping applied to the ankle in stroke patients for 24 hours has been reported to improve the displacement 
Table 2. Changes in the Dynamic Abilities of the Two Intervention Groups

\begin{tabular}{|c|c|c|c|c|}
\hline & & Experimental group $(\mathrm{n}=10)$ & Control group $(n=10)$ & $p$ \\
\hline \multirow{2}{*}{ Forward sway area $\left(\mathrm{mm}^{2}\right)$} & Before & $1173.40 \pm 922.82^{\mathrm{a})}$ & $1502.90 \pm 1056.20$ & .467 \\
\hline & After & $1266.70 \pm 970.22$ & $1529.30 \pm 999.03$ & .558 \\
\hline \multirow{6}{*}{ Backward sway area $\left(\mathrm{mm}^{2}\right)$} & Change & $93.30 \pm 113.12$ & $26.40 \pm 225.06$ & \\
\hline & $p$ & $.028 *$ & .719 & \\
\hline & Before & $1042.90 \pm 782.56$ & $1376.30 \pm 1092.58$ & .443 \\
\hline & After & $1124.80 \pm 799.10$ & $1403.80 \pm 1044.58$ & .511 \\
\hline & Change & $81.90 \pm 125.37$ & $27.50 \pm 164.73$ & \\
\hline & $p$ & .069 & .610 & \\
\hline \multirow{2}{*}{ Paretic side swayarea $\left(\mathrm{mm}^{2}\right)$} & Before & $1020.40 \pm 837.34$ & $1656.80 \pm 1903.20$ & .181 \\
\hline & After & $1169.90 \pm 992.03$ & $1803.20 \pm 1143.51$ & .202 \\
\hline \multirow{6}{*}{ Non-paretic side swayarea $\left(\mathrm{mm}^{2}\right)$} & Change & $149.50 \pm 307.28$ & $146.40 \pm 344.95$ & \\
\hline & $p$ & .158 & .212 & \\
\hline & Before & $1371.20 \pm 1505.80$ & $1886.90 \pm 1386.56$ & .415 \\
\hline & After & $1505.80 \pm 1544.29$ & $2033.30 \pm 1292.48$ & .511 \\
\hline & Change & $134.60 \pm 244.60$ & $146.40 \pm 342.02$ & \\
\hline & $p$ & .116 & .209 & \\
\hline
\end{tabular}

${ }^{\text {a) Values are means } \pm \text { SD. }}$

*Significant difference between before and after intervention in each group $(p<.05)$.

‡Significant difference between the experimental and control groups $(p<.05)$.

Experimental group: A-P talocrural joint mobilization with elastic taping.

Control group: Elastic taping only.

of the COP (Rojhani-Shirazi et al., 2015). On the other hand, a tape application time of $30 \mathrm{~min}$ did not improve the gait of stroke patients (Park, 2017). The present study applied elastic tape for only $30 \mathrm{~min}$ in order to reduce interference with other therapies, and there were no significant changes in sway results in the control group. Therefore, application of tape for $30 \mathrm{~min}$ appears to be insufficient for improving balance ability in stroke patients.

However, the experimental group, in which joint mobilization and taping were combined, exhibited a significant improvement in forward sway area. Passive joint mobilization may have an effect on ROM enhancement but has no effect on functional activity (Kluding and Zipp, 2004). Joint mobilization applied to the talus of stroke patients has produced an increase in the forward area of the LOS (An and Jo, 2017). Because A-P talocrural joint mobilization is capable of correcting a positional defect of the talus, it may increase the ankle dorsiflexion ROM in ankle immobilization patients (Landrum et al., 2008). Passive movements in joints can change viscoelasticity and reflexive responses (Nuyens et al., 2002). Therefore, repeated movements of the joint through joint mobilization may result in a change in viscoelasticity (Nuyens et al.,2002), which may reduce calf spasticity (Pérez Parra and Henao Lema, 2011). However, those changes may be the result of ankle joint correction (Landrum et al., 2008). In addition, since calf muscle taping has been shown to recover balance on the A-P plane (Cortesi et al., 2011), it seems that the taping assisted in improving sway area when moving in the forward direction. 
Compared to conventional therapy alone, conventional joint mobilization therapy applied to the ankle joint is a more effective intervention method for ankle kinetics and weight-bearing ability (An and Jo, 2017). Several previous studies have emphasized the importance of joint movement in limiting ankle joint movements in stroke patients and have demonstrated the effectiveness of joint movement in balance and gait function (Kim and Lee, 2018). However, in previous studies, joint mobilization was applied with weight-bearing or as mobilization with movement (MWM) (An and Jo, 2017; Kim and Lee, 2018). Because balance decreases in stroke patients as the severity of the patient condition increases (Tyson et al., 2006), MWM may be difficult to apply in a weight-bearing state when the patient lacks balance ability. Therefore, in cases where MWM is inapplicable, A-P passive mobilization to be applied in the lying-on-stomach position, similar to that in this study, is recommended with elastic tape applied as an additional measure.

There was no significant difference between the results of the experimental and control groups in this study. Thus, the study failed to show a difference between the two intervention methods tested, perhaps because the intervention period was immediate. Regardless, the combination intervention did produce an increase in the forward sway area.

A major limitation of this study was the small number of subjects. In addition, the study did not investigate whether the BioRescue system was effective in showing an improvement in balance ability. Therefore, future study should confirm its usefulness for both the dynamic and static balance assessment.

\section{Conclusion}

The present study was conducted to investigate the effect of a combination of A-P talocrural joint mobilization and elastic taping on the balance ability of stroke patients.
Twenty stroke patients were recruited and divided into two groups: joint mobilization with taping group $(\mathrm{n}=10)$ and elastic taping only group $(\mathrm{n}=10)$. Joint mobilization with taping improved forward sway area of the stroke patients. However, there was no significant difference between the two groups. In general, stroke patients exhibit a decrease in balance ability. A-P talocrural joint mobilization performed in the supine position is a passive movement, thus it is safe to apply to stroke patients. In addition to joint mobilization, elastic taping should be applied to assist in restoring balance ability.

\section{References}

An CM, Jo SO. Effects of talocrural mobilization with movement on ankle strength, mobility, and weight-bearing ability in hemiplegic patients with chronic stroke: a randomized controlled trial. J Stroke Cerebrovasc Dis. 2017;26(1):169-76.

Bohannon RW, Smith MB. Interrater reliability of a modified Ashworth scale of muscle spasticity. Phys Ther. 1987;67(2):206-7.

Chien $\mathrm{CW}$, Hu MH, Tang PF, et al. A comparison of psychometric properties of the smart balance master system and the postural assessment scale for stroke in people who have had mild stroke. Arch Phys Med Rehabil. 2007;88:(3):374-80.

Cortesi M, Cattaneo D, Jonsdottir J. Effect of kinesio taping on standing balance in subjects with multiple sclerosis: a pilot study. Neuro rehabilitation. 2011;28(4):365-72.

Denegar CR, Hertel J, Fonseca J. The effect of lateral ankle sprain on dorsiflexion range of motion, posterior talar glide, and joint laxity. J Orthop Sports Phys Ther. 2002;32(4):166-73.

Hengenveld E, Banks K. Maitland's Peripheral Manipulation (4th ed). Butterworth-heinemann Elsevier. 2005..

Jaraczewska E, Long C. Kinesioß taping in stroke: improving functional use of the upper extremity in hemiplegia. 
Topics in Stroke rehabilitation. 2006;13(3):31-42. Kang Y, Na DL, Hahn SH. A validity study on the Korean mini-mental state examination (K-MMSE) in dementia patients. J Korean Neurol Assoc. 1997;15(2): 300-8.

Kim SL, Lee BH. The effects of posterior talar glide and dorsiflexion of the ankle plus mobilization with movement on balance and gait function in patient with chronic stroke: a randomized controlled trial. J Neurosci Rural Prac. 2018;9(1):61-7.

Kluding P, Zipp GP. Effect of ankle joint mobilization on ankle mobility and sit-to-stand in subjects with hemiplegia. Journal of Neurologic Physical Therapy. 2004;28(2):72-83.

Koseoglu BF, Dogan A, Tatli HU, et al. Can kinesio tape be used as an ankle training method in the rehabilitation of the stroke patients? Complement Ther Clin Prac. 2017;27:46-51.

Landrum EL, Kelln BM, Parente WR, et al. Immediate effects of anterior-to-posterior talocrural joint mobilization after prolonged ankle immobilization: a preliminary study. J Man Manip Ther. 2008;16(2):100-5.

Lee JH, Park SJ. Examining the Quality of Life Related to Fall Experience in Chronic Stroke Patients. J Korean Soc Phys Med. 2016;11(3):73-80.

Lin PY, Yang YR, Cheng SJ, et al. The relation between ankle impairments and gait velocity and symmetry in people with stroke. Arch Phys Med Rehabil. 2006;87(4):562-8.

Liston RA, Brouwer BJ. Reliability and validity of measures obtained from stroke patients using the Balance Master. Arch Phys Med Rehabil. 1996;77(5):425-30

Middleton A, Braun CH, Lewek MD, et al. Balance impairment limits ability to increase walking speed in individuals with chronic stroke. Disabil Rehabil. 2017;39(5): 497-502.

Norkin JW, White J. Measurement of Joint Motion: A Guide to Goniometry, 4th Edition F.A. Davis Company. 2009.
Nuyens GE, De Weerdt WJ, Spaepen AJ, et al. Reduction of spastic hypertonia during repeated passive knee movements in stroke patients. Arch Phys Med Rehabil. 2002;83(7):930-5.

Oliveira CB, Medeiros IRT, Frota NAF, et al. Balance control in hemiparetic stroke patients: main tools for evaluation. Journal of rehabilitation research and development. 2008;45(8):1215-26.

Park SJ, Kim SH, Min KO. Effects of joint mobilization and respiratory muscle taping on pulmonary function and chest expansion ability in patients with chronic stroke. J Int Acad Phys Ther Res. 2017;8(3):1229-34.

Park SJ, Youn PS. The immediate effect of wrist joint mobilization with taping on range of motion, grip strength, spasticity in stroke patients. J Korean Phys Ther. 2017;29(4):187-93.

Park SJ. The immediate effects of proprioceptive neuromuscular facilitation with taping on gait parameters in patients with chronic stroke. J Phys Ther Sci. 2017;29(11): 2018-21.

Pérez Parra JE, Henao Lema CP. Effect of joint mobilization on the H Reflex amplitude in people with spasticity. Rev Cienc Salud. 2011;9(2):125-40.

Rojhani-Shirazi Z, Amirian S, Meftahi N. Effects of ankle kinesio taping on postural control in stroke patients. J Stroke Cerebrovasc Dis. 2015;24(11):2565-71.

Song CH, Lee GC, Yoo JH, et al. The Relation Between Postural Sway and Asymmetric Weight-bearing for Fall Prevention in Patients with Stroke. J Korean Soc Phys Med. 2010;5(1):81-8.

Song GB, Park EC. The effects of balance training on balance pad and sand on balance and gait ability in stroke patients. J Korean Soc Phys Med. 2016;11(1):45-52.

Tyson SF, Hanley M, Chillala J, et al. Balance disability after stroke. Phys Ther. 2006;86(1):30-8.

Yildizgoren MT, Velioglu O, Demetgul O, et al. Assessment of the anterior talofibular ligament thickness in patients with chronic stroke: an ultrasonographic study. J Med Ultrasound. 2017;25(3):145-9. 